\title{
Coleção de Nuvens: considerações sobre os procedimentos arquivísticos baudelairianos
}

Frederico Canuto (Instituto Metodista Izabela Hendrix / UFMG)

Resumo: O presente artigo pretende abordar o tema do colecionismo presente na poesia Baudelairiana a partir dos conceitos de fisiologia, colecionador e alegorista desenvolvidos por Walter Benjamin. A questão central que está a se cartografar e desenvolver é a maneira como Charles Baudelaire cria imagens ambíguas ou pontos de contato entre passado e presente, real e imaginário na cidade a partir de suas criações poéticas, tomando como recorte conceitual a noção de reminiscência no texto "Teses sobre a História".

Palavras-chave: Cidade, Poesia, História

\begin{abstract}
"Nesse gênero do folhetim [sic] ocupavam lugar privilegiado os fascículos de aparência insignificante, e em formato de bolsos chamados de 'fisiologias'. Ocupavam-se da descrição dos tipos encontrados por quem vai a feira. Desde o vendedor ambulante do bulevar até o elegante no foyer da ópera, não havia nenhuma figura da vida parisiense que o 'fisiólogo' não houvesse retratado. [...]É a escola superior do folhetim, pelo qual passou a geração de Baudelaire. Que tinha pouco a lhe dizer, mostra-o ter ele, cedo ainda, seguido seu próprio caminho. [...] A calma destas descrições combina com o jeito do flâneur, a fazer botânica no asfalto."
\end{abstract}

O Flâneur, "cronista e filósofo", no meio da multidão passante na rua cria possibilidades a partir de onde nada brota, segundo Benjamin. Animais, pessoas, espaços são matéria-prima na criação poética de novas situações da vida na Modernidade através das operações da flânerie tecendo, "a seu modo, a fantasmagoria da vida parisiense", construindo fisiologias. As galerias de Paris, por exemplo, "caminhos cobertos de vidro e revestido por mármore, através de blocos de casas [...] onde de ambos os lados se estendem os mais elegantes estabelecimentos comerciais", espaço de exposição e circulação de mercadorias, pessoas e força de trabalho se transforma nestes folhetins de formato de bolso, em interiores para uma vida pública, onde

“[...]os letreiros esmaltados e brilhantes das firmas são um adorno de parede tão bom ou melhor que a pintura a óleo no salão do burguês; muros são a escrivaninha onde apóia o loco de apontamentos; bancas de jornais são suas bibliotecas, e os terraços dos cafés, as sacadas de onde, após o trabalho, observa o ambiente" ${ }^{2}$.

Cadernos Benjaminianos, n. 3, Belo Horizonte, jan.-jun. 2011, p.55-62 
As operações fisiológicas se assemelham à criação poética do flâneur. As fisiologias se constituem uma nova possibilidade de olhar para com a cidade dentro da vida cotidiana de paralelepípedos cinzentos e ante o cinzento pano de fundo do despotismo por meio do sarcasmo e de uma inofensiva e completa bonomia ${ }^{3}$, dirá Benjamin. A salvação do passado, ligando ao mesmo tempo em que descartando-o como imagem inapreensível, posto que é perdido, analogamente diz da retomada do espaço da rua através da irônica fisiologia do interior da galeria, em contraposição a raridade das calçadas largas após a reforma Haussmaniana nos anos 1870. Uma recuperação atualizada dada pela flânerie no pequeno folhetim.

Sobre a relação entre o passado e o presente, Lowy, comentando a tese 05 do texto Teses sobre a História de Benjamin que versa sobre a imagem do passado que perpassa veloz e que só se deixa fixar no momento de seu próprio reconhecimento ${ }^{4}$, dirá das semelhanças guardadas entre o autor alemão e Proust na medida em que a

“[...] salvação do passado [sic] no presente, [se dá] graças a percepção de uma semelhança que transforma os dois. Transforma o passado porque este assume uma nova forma, que poderia ter desaparecido no esquecimento; transforma o presente porque este se revela como a realização possível da promessa anterior - uma promessa que poderia se perder para sempre, que ainda pode ser perdida se não for descoberta inscrita nas linhas atuais" ${ }^{5}$.

Do que resta do passado, a semelhança pontual unificadora com o presente pelo olhar do historiador se dá no momento de apropriação de suas reminiscências ${ }^{6}$. Nesta operação, o texto poético se constituirá como ponto de convergência desta escrita ocupada em atualizar o que passou, presentificando-o. Este é o ponto onde se localiza a fisiologia e a poesia, produto da operação dada pelo flâneur. Ponto de aproximação e base para posterior distanciamento visto que são escritas de forma diferenciadas.

Benjamin fará seu trabalho de historiador de uma Paris Novecentista a partir do princípio das semelhanças, transversalmente à linearidade histórica então, ao basear sua escritura em correspondências a partir de imagens de outros no XIX, entre eles, Baudelaire. O poeta francês operará da maneira semelhante, com imagens vindas de um ideal romântico de natureza e pureza em contraponto às imagens da pintura e do espetáculo da moda do século XIX, por exemplo, construindo uma noção de presente que coloca tais termos em uma relação de ambivalência ${ }^{7}$. Sua construção poética, segundo Auerbach, em As Flores do Mal obedece a construção de paradoxos na medida em que a representação é calculada e construída de forma tradicional ao mesmo tempo em que os temas tratados são baixos, com ironias a todo momento ${ }^{8}$. Articular numa mesma forma poética a tradição e a vida na cidade. Organismo estranho à natureza romântica transforma-se algo novo para a poesia no século XIX. Sarcasmos inofensivos tais como as fisiologias da cidade que dizem de uma nova surgente no uso de letreiros esmaltados e brilhantes.

Assim, colocará Benjamin, a poética baudelairiana faz um deslocamento, aproximando do que se apresenta na vida cotidiana, vendo a rapidez das transformações, provando que “[...] Baudelaire está incrustado no século XIX”, onde "A impressão que nele deixou deve surgir tão nítida e intacta como a de uma pedra que, certo dia, é movida de seu lugar depois de aí ter jazido por décadas"9. Ou seja, a marca da pedra, vestígio, é o que está presente do passado, é o presente e não mais a pedra como figura do passado. Entre o próximo e o distante, o que resta é a marca do 
deslocamento da pedra de um lugar a outro. Portanto, uma imagem que diz da natureza não como idealidade ou transcendência, mas como artifício dado pela ação humana que sofre a ação do tempo. Não há mais metafísica e falta de uma dimensão temporal, mas marcas de um tempo, de um deslocamento, que altera a percepção do presente. Em "O Crepúsculo Romântico", da beleza do sol à ausência divina e terra coberta de répteis asquerosos, o poeta constrói uma descida do atemporal rumo a história de marcas do tempo experimentado pelo odor nas trevas da mundanidade:

"Quão belo é o sol quando no céu se ergue risonho, E qual uma explosão nos lança o seu bom-dia! - Feliz quem pode com amor e ébria alegria Saudar-lhe o ocaso mais glorioso do que um sonho!

Recordo-me! Eu vi tudo, a flor, o sulco, a fonte, Murchar sob o esplendor dessa pupila que arde... - Corramos todos sem demora ao poente, é tarde, Para abraçar um raio oblíquo no horizonte!

Mas eu persigo em vão o Deus que ora se ausenta; A irresistível Noite o seu império assenta, Úmida, negra, erma de estrelas ou faróis;

Um odor de sepulcro em meio às trevas vaga, E junto aos pantanais meu pé medroso esmaga Inesperadas rãs e frios caracóis" ${ }^{\prime 10}$.

Desta maneira, a poesia de Baudelaire não se enquadra no ideal romântico de natureza compreendida pela religiosidade ou fatalismo, mas "murcha" e adere às coisas menores, mundanas, próximas a rés do chão, consciente da própria impossibilidade de uma metafísica, pois "eu vi tudo [...] murchar".

Concomitantemente, as figuras que Baudelaire irá usar para cortar a vida no Auge do Capitalismo a fim de contar de uma experiência proximal não serão as relacionadas aos heróis da grande história, "sol que se ergue risonho", mas aos mais ordinários e mundanos, "junto aos pantanais que meu pé esmaga". Nessa mudança de a partir de onde olhar, as imagens que o poeta francês produzirá em suas poesias não terão como ponto nodal os personagens, mas as experiências próximas e menores pelos quais se passa na Modernidade através destes personagens.

Assim, Baudelaire coleciona os tipos da cidade para enquadrá-los literariamente como experiências marginais de uma Modernidade em desenvolvimento, montando um arquivo a partir dos vestígios do passado e dos restos pela Modernidade no presente, das marcas do passado, obtidos numa leitura a contrapelo da história. O flâneur e o trapeiro são vidas literárias capazes de suportar e produzir uma vida coletiva, falar de uma experiência coletiva perdida [Erfahrung] tal qual a lamentada por Benjamim ${ }^{11}$.

Tais personagens são as alegorias através dos quais será possível pensar a Paris do século XIX, dirá Walter Benjamin, constituindo-se traduções, no sentido benjaminiano, da boemia parisiense. Da mesma maneira que os fragmentos de uma ânfora, para que se possa reconstituir o todo, devem combinar uns com os outros nos mínimos detalhes, apesar de não precisarem ser iguais, a tradução, em lugar de se 
fazer semelhante ao sentido do original, deve, de maneira amorosa e detalhada, passar para a sua própria língua o modo de significar do original; assim como os pedaços partidos são reconhecíveis como fragmentos de uma mesma ânfora, o original e a tradução devem ser identificados como fragmentos de uma linguagem maior. $^{12}$

\section{A Boemia e o trapeiro, o flâneur...objetos colecionáveis}

Em "vinho dos trapeiros" 13 , o personagem é o bêbado que sob o efeito alcoólico "onde fervilha o povo anônimo e indistinto", esgueira-se nas paredes tal qual um poeta. Este trapeiro, que ao tomar o vinho entorpece-se e torna-se outro, transfigurase e põe-se a falar "desses malditos que em silêncio vão morrendo". Ele, "abre seu coração em projetos gloriosos" a fim de "na ensurdecedora e luminosa orgia, Do clarim e do sol, do grito e do tambor, trazer [sic] a glória ao povo ébrio de amor!".

O trapeiro, segundo Benjamin, não é uma figura que pertence a classe dos conspiradores, daqueles que se encontram nas tavernas dos negociantes dos vinhos, fazem barricadas e mudam a história. Ele é aquele que viaja até a periferia parisiense a fim de tomar vinhos a preços mais acessíveis, os vinhos de barreira, pois os impostos foram aumentados pelo governo ${ }^{14}$. É então aquele que não participa de grandes estratégias e esquemas de revolta, as conspirações coletivas como as organizadas pelos operários no século XIX. Em seu cotidiano mundano, em suas ações próximas e repetidas, inventa táticas e estratégias de sobrevivência nas trevas, junto aos pantanais "das inesperadas rãs frios caracóis". Num nível micropolítico, age como "o que Baudelaire assim registra poder-se-ia denominar metafísica do provocador [grifo nosso]"15. Provocador este que ativa a pequena parte escondida em todos, onde" [...]desde o liberato até o conspirador profissional, cada um que pertencesse a boêmia podia reencontrar no trapeiro um pedaço de si mesmo" ${ }^{\text {"16 }}$. Ou seja, o trapeiro é aquele que tem visibilidade e passa despercebido pois não catalisa desejos, mas potencialmente é o que na proximidade das relações políticas humanas, responde provocando outros.

Da mesma maneira, o flâneur não faz grandes discursos sobre a experiência da cidade, buscando organizar revoltas. Sua experiência, muito mais do que inferir transformações numa macroescala, busca uma clareza critica a partir do tomar parte da multidão do ponto de vista estético-político. Sua capacidade ao estar junto aos passantes é aferir valores à experiência de deslocamento e anonimato que a nova realidade produz.

Assim, os objetos que interessam tanto a Benjamin como a Baudelaire são determinados na medida em que são capazes de atravessar grandes narrativas e atingir a vida próxima, mundana, lócus de desenvolvimento da Modernidade. São pontos nodais não o personagem em si, mas o tipo de efeito estético por ele desempenhado na criação poética que o autor parisiense produz em $\underline{\text { As Flores do }}$ Mal. São objetos não como mercadorias para trocas mas como atravessadores, base para uma coleção de fisiologias irônicas.

\section{O Colecionador e o Alegorista: arquivistas de nuvens}

"O grande colecionador é tocado bem na origem pela confusão, pela dispersão em que se encontram as coisas no mundo. [...] O alegorista é por assim dizer o pólo oposto ao colecionador. Ele desistiu de elucidar as 
coisas através da pesquisa do que lhes é afim e do que lhes é próximo. Ele as desliga de seu contexto e desde o princípio confia na sua meditação para elucidar o seu significado. O colecionador, ao contrario, reúne as coisas que são afins; consegue, deste modo, informar a respeito das coisas através de suas afinidades ou de sua sucessão no tempo. No entanto, $[\ldots]$ em cada colecionador esconde-se um alegorista e em cada alegorista, um colecionador." 17 .

Ao aproximar e intercalar as figuras do colecionador e alegorista, depreende-se que no interior de cada alegorista, como Benjamin considera Baudelaire ${ }^{18}$, existe um ordenador. Tal como o alegorista que medita para encontrar nas coisas um significado, presentificando-as; paralelamente uma ordenação do conhecimento ao se tocar a dispersão do mundo também é construída pois como colecionador, nele reside a tarefa de reunir coisas afins ou que se sucedem no tempo.

A cidade que é percorrida é aquela cujo interior e exterior intercalam-se pois "se no começo, as ruas se transformam para ele em interiores, agora são esses interiores que se transformam em ruas e, através do labirinto de mercadorias, ele vagueia como outrora através do labirinto urbano"19. Como colocado pelo poeta francês em "Os Sete Velhos" ${ }^{\text {,20 }}$ que caminha por entre as figuras que lhe aparecem à frente, vê sete monstros, talvez oito, e

"Furioso como um ébrio que vê dois em tudo, Entrei, fechei a porta, Trêmulo e perplexo, Trânsito e enfermo, o espírito confuso e mudo, Fendido por mistérios e visões sem nexo!

Minha razão debalde ao leme se agarrava;

A tempestade lhe rompia a quilha e as cordas,

E minha alma, ó naufrágio, dançava, dançava,

Sem mastros, sobre um mar fantástico e sem bordas!”.

Ao ver dois em tudo, volta e se tranca, "fendido por mistérios e visões sem nexo". Percebe a rua como perigo ao mesmo tempo que, ao final, a olha como espaço que lhe faz romper quilhas e cordas, fazendo-o dançar sobre "um mar fantástico e sem bordas". O poeta então cria um significado ao que um primeiro momento, multiplicado, o fazia tremular. Ao mesmo tempo, esconde-se atrás desta alegoria, um objeto a colecionar: o flâneur que ao ver sete começarem a se multiplicar, perdese para depois compreender tal perdição e dar-lhe um nome, um naufrágio num barco sem mastro.

Mais do que um objeto da coleção baudelairiana, o flaneur é um corte dentro desta coleção de tipos. Tal como um colecionador de posse dos objetos encontrados e recolhidos no mundo cortando tal dispersão de forma a construir uma organização própria, segundo parâmetros seus, o alegorista aqui usa da meditação e compreensão do que é dado para montar sua própria compreensão da realidade. "Como flâneur, ele se identificou com a alma da mercadoria; como alegorista, reconhece na 'etiqueta com preço', com o qual a mercadoria era no mercado, o objeto de sua meditação: seu significado" ${ }^{21}$. Primeiro, identificar-se com a rua, mercadoria e locus de mercadorias, e extrai dela significados. Depois, colecionar fisiologias da cidade que falam de vários significados a partir de um mesmo corte deambulante, tal como o 
flâneur: "Paris à Noite, Paris à Mesa, Paris na Água, Paris a Cavalo, Paris Pitoresca, Paris Casada",22.

O flâneur, sem determinação política ou econômica, operador construtivo de fisiologias, deve ser ambíguo de acordo com o contexto a que ele está colado. Curva-se ao mercado ao mesmo tempo que faz parte dos conspiradores da boemia, não respondendo a uma classe especificamente, seja dos dominantes ou dominados. Utiliza-se de tal indeterminação e ambigüidade política para simular possíveis meditações. Incorporar resultados de tais ambivalências na poesia através da alegoria e de um pequeno objeto colecionável é o que Baudelaire faz. Esta figura da multidão da Paris Novecentista prefere amar o transitório numa era de transitoriedades, um estrangeiro que não reside em local nenhum como dirá Baudelaire:

“- A quem você ama mais, homem enigmático, me diga: seu pai, sua mãe, sua irmã ou seu irmão?

Não tenho pai, nem mãe, nem irmã, nem irmão.

Seus amigos?

O senhor está utilizando uma palavra com sentido até hoje é desconhecido para mim.

Sua pátria?

Ignoro sob qual latitude está situada.

A beleza?

Eu a amaria com prazer, deusa e imortal.

Eu o odeio como o senhor odeia a Deus.

Ei! O que é então que você ama, extraordinário estrangeiro?

Amo as nuvens... as nuvens que passam.... lá, lá, adiante... as maravilhosas nuvens!"23.

Um amante das nuvens é o que se pode esperar de um poeta cujo modo de operar é a flânerie pois amar as nuvens é o ponto de contato entre passado e presente, em estado de desaparecimento, marca da pedra ao ser retirada. É estado transitório e movente. Ao "[...] usar a imaginação, a mais científica das faculdades, pois só ela compreende a analogia universal, ou aquilo que uma religião mística denomina correspondance", ${ }^{24}$ uma categorização está sendo proposta, um arquivo de nuvens está em processo de feitura, uma coleção de ar, uma névoa que passa lentamente ao chover.

Abstract: This article aims to address the issue of collecting in Baudelaire's poetry with the concepts of physiology, collector and allegory developed by Walter Benjamin. The central question is understand how Charles Baudelaire creates ambiguous images or contact points between past and present, real and imaginary in the city from his poetic creations, taking the conceptual notion reminiscence from the text "Theses on History".

Cadernos Benjaminianos, n. 3, Belo Horizonte, jan.-jun. 2011, p.55-62 
Keywords: City, Poetry, History

\section{Referências Bibliográficas}

AUERBACH, E. Ensaios de Literatura Ocidental. São Paulo: 34, 2007.

BAUDELAIRE, Charles. As Flores do Mal. Rio de Janeiro: Nova Fronteira, 2006.p.351 e 353 .

BAUDELAIRE, Charles. Pequenos Poemas em Prosa [o spleen de Paris]. São Paulo: Hedra, 2007.BENJAMIN, Walter. A Tarefa do Tradutor IN: Cadernos de Mestrado UERJ, n.01, p.XVII-XVIII.

BENJAMIN, Walter. Obras Escolhidas 01. Magia e Técnica. Arte e Política. São Paulo: Brasiliense, 1994.

BENJAMIN, Walter. Obras Escolhidas 03. Charles Baudelaire: Um Lírico no Auge do Capitalismo. São Paulo: Brasiliense, 1989.

BENJAMIN, Walter. Passagens. Belo Horizonte, São Paulo: EdUFMG, Imprensa Oficial, 2007.

DAMIÃO, Carla. Sobre o Declínio da Sinceridade. Filosofia e Autobiografia de JeanJacques Rosseau a Walter Benjamin. São Paulo: Loyola, 2006.

GAGNEBIN, Jeanne Marie. Lembrar, Escrever, Esquecer. São Paulo: 34, 2006.

GAGNEBIN, Jeanne Marie. História e Narração em Walter Benjamin. São Paulo: Perspectiva: 2004.

LOWY, Michael. Walter Benjamin: Aviso de Incêndio. Uma Leitura das Teses "Sobre o Conceito de História”. São Paulo, Boitempo, 2005.

MISSAC, Pierre. Passagem de Walter Benjamin. São Paulo: Iluminuras, 1998.

MOLDER, Maria Filomena. Semear na Neve. Estudos sobre Walter Benjamin. Lisboa: Relógios D'água, 1999.

SARLO, Beatriz. Cultura da Memória e Guinada Subjetiva. Belo Horizonte: EdUFMG; São Paulo: Companhia das Letras, 2007.

\section{Notas}

${ }^{1}$ BENJAMIN, Walter. Obras Escolhidas 03. Charles Baudelaire: Um Lírico no Auge do Capitalismo. p.34.

${ }^{2}$ Ibid Idem.

Cadernos Benjaminianos, n. 3, Belo Horizonte, jan.-jun. 2011, p.55-62 
${ }^{3}$ Ibid Idem.

${ }^{4}$ BENJAMIN, Walter. Obras Escolhidas 01. Magia e Técnica. Arte e Politica. p.224.

${ }^{5}$ GAGNEBIN, Jeanne Marie. Walter Benjamin ou a História Aberta apud LOWY,

Michael. Walter Benjamin: Aviso de Incêndio. Uma Leitura das Teses "Sobre o Conceito de História". p.63.

${ }^{6}$ Sobre reminiscência, Benjamin colocará em Teses sobre a História na tese 06, "Articular historicamente o passado não significa conhecê-lo 'como ele de fato foi'. Significa apropriar-se de uma reminiscência, tal como ela relampeja num momento de perigo." [BENJAMIN, Walter. Obras Escolhidas. Magia e Técnica. Arte e Política. p.224.]

${ }^{7}$ Sobre ambivalência, termo desenvolvido na psicanálise para descrever a continua flutuação entre o querer algo e querer seu oposto, se referindo também a uma simultânea atração por e repulsão de um objeto.

${ }^{8}$ Cf. AUERBACH, E. Ensaios de Literatura Ocidental.

${ }^{9}$ BENJAMIN, Walter. Passagens. p.366.

${ }^{10}$ BAUDELAIRE, Charles. As Flores do Mal. p.463.

${ }^{11}$ cf. Experiência e Pobreza e O Narrador. Considerações sobre a Obra de Nicolai Leskov IN: BENJAMIN, Walter. Obras Escolhidas 03. Charles Bauldelaire: Um Lirico no Auge do Capitalismo. Em ambos, o autor lamenta a perda de um tipo de experiência própria da pré-Modernidade, a ehrfarung, determinada por três pré-condições dirá GAGNEBIN no prefácio deste mesmo livro no texto 'Walter Benjamin ou a História Aberta': a experiência transmitida pelo relato deveria ser comum ao narrador e ao ouvinte; o apoio da comunidade entre vida e palavra numa organização pré-capitalista do trabalho, em especial artesanal; e a fundação da experiência na dimensão prática da narrativa tradicional.

${ }^{12}$ BENJAMIN, Walter. A Tarefa do Tradutor. p.XVII-XVIII.

${ }^{13}$ BAUDELAIRE, Charles. As Flores do Mal. p.351 e 353.

${ }^{14}$ BENJAMIN, Walter. Obras Escolhidas 03. Charles Baudelaire: Um Lírico no Auge do Capitalismo. p.15,16.

${ }^{15}$ Ibid Idem. p. 11 .

${ }^{16}$ Ibid Idem. p. 17.

${ }^{17}$ BENJAMIN, Walter. Passagens. p.245.

${ }^{18}$ Ibid Idem. p.414.

${ }^{19}$ BENJAMIN, Walter. Obras Escolhidas 03. Charles Baudelaire: Um Lírico no Auge do Capitalismo. p.51.

${ }^{20}$ BAUDELAIRE, Charles. As Flores do Mal. p.309.

${ }^{21}$ BENJAMIN, Walter. Passagens. p.414.

${ }^{22}$ BENJAMIN, Walter. Obras Escolhidas 03. Charles Baudelaire: Um Lírico no Auge do Capitalismo. p.34.

${ }^{23}$ BAUDELAIRE, Charles. Pequenos Poemas em Prosa [o spleen de Paris]. p.37.

${ }^{24}$ BENJAMIN, Walter. Passagens. p.287. 